\title{
Evaluation of Genetic Variability in Tomato (Solanum lycopersicum L. Mill) Genotypes using Microsatellite Markers
}

\author{
Pooja Choudhary ${ }^{1}$, Gyanendra Kumar Rai ${ }^{{ }^{*}}$, Sreshti Bagati ${ }^{1}$, Deeksha Jamwal ${ }^{1}$, \\ Diksha Bhadwal ${ }^{1}$, Vibha Raj Shanti ${ }^{1}$ and Pradeep Kumar Rai ${ }^{2}$ \\ ${ }^{1}$ School of Biotechnology, SKUAST-Jammu, J\&K - 180009, India \\ ${ }^{2}$ ACHR, SKUAST-Jammu, Udheywala, Jammu J\&K - 180002, India \\ *Corresponding author
}

\begin{abstract}
A B S T R A C T
Tomato (Solanum lycopersicum L.) is one of the most important economically plants in the family Solanaceae. Information about genetic diversity of any crop is important for successful employment of breeding programme and is of great significance to attain sustainability in crop production. The objective of this study was to evaluate the genetic diversity of 24 genotypes of tomato collected from ICAR-IIVR, Varanasi, India, using 25 simple-sequence repeats (SSRs). A total of 64 alleles were detected at an average of 2.720 alleles per SSR locus. The average major allele frequency and polymorphic information content were 0.6622 and 0.3875 , respectively. The UPGMA cluster analysis induced by SSRs data grouped 24 tomato genotypes into 3 main clusters. Cluster I and II comprised 15 and 8 genotypes respectively, and a single tomato genotype CO-3 was grouped in cluster III. As per our expectation genotypes from same genetic base showed similarity among each other. The information obtained from SSR markers may well assist tomato breeders in identifying a limited number of highly differentiated genotypes to be selected for further use in developing suitable variety/genotypes with good quality potential.
\end{abstract}

\section{Introduction}

Tomato, a popular garden vegetable, is an herbaceous plant belonging to family Solanaceae. It is a second most cultivated vegetable crop across the globe (Foolad, 2007; Rai et al., 2012). Out of the total vegetable production in the world, approximately $14 \%$ accounts for tomato (Osei et al., 2014). Being a vegetable of multipurpose utility in food and processing industries, tomato is also a rich source of phytonutrients for human consumption. At present, tomato breeders aim at improving yield, fruit quality characteristics as well as tolerance towards biotic and abiotic stresses for which a prior apprehension of the existing genetic diversity within the tomato cultivars is a prerequisite (Foolad, 2007; Rai et al., 2016). A precise evaluation of the variability in the tomato germplasm is of immense importance for the ongoing as well as subsequent crop improvement programmes for agronomic and genetic improvement of the crop (Reddy et al., 2013). The availability of the completely sequenced genome and its enormous agricultural and economic 
importance has made tomato a pre- eminent model for genetics, genomics and breeding studies (Henarehet.al. 2015).For the identification and estimation of genetic diversity various morphological, biochemical and molecular markers can be used. One of the important diagnostic features for differentiating genotypes are the morphological traits (Osei et al., 2014), however, their efficiency is primarily influenced by environmental factors. With the advent of marker technology, the use of methods for diversity estimation has been extended from unstable morphological traits to stable biochemical and molecular traits. Several molecular marker viz. RFLP, RAPD, SSRs, ISSRs, AFLP and SNPsare presently available to assess the variability and diversity at molecular level, among which SSR markers are the most widely used (Frary et al., 2005). Earlier studies have reported the use of morphological and molecular markers viz. SSRs for unraveling the genetic diversity in tomato germplasm (Agong et al., 2001; Bredemeijer and Cooke, 2002; He et al., 2003; Song et al., 2006; Mazzucato et al., 2008; AlAysh et al., 2012). Dissection of the genetic diversity within the tomato germplasm will be useful in varietal identification, in deciphering the extent of genetic variation, in the construction of genetic linkage maps and in hybridization programmes (Naz et al., 2013). The present study aimed at unraveling the existing genetic diversity within the tomato genotypes using microsatellite markers.

\section{Materials and Methods}

\section{Plant material}

A total of 28 tomato genotypes (Table 1, were used in this study. These genotypes were procured from Indian Institute of Vegetable Research (IIVR) Varanasi. All the genotypes were grown in a randomized complete block design (RCBD) with three replicates.

\section{Molecular analysis}

\section{DNA extraction}

The young leaves of common bean genotypes were powdered in liquid nitrogen and the genomic DNA was extracted based on the procedure of Doyle and Doyle with little modifications. The DNA quantity as well as quality was checked by Nanodrop (mySPEC, Wilmington, USA). Isolated high quality DNA was diluted to concentration of $25 \mathrm{ng} / \mu \mathrm{l}$ for further use.

\section{SSR analysis}

SSR primers synthesized at IDT (Integrated DNA Technologies, USA) were used for studying polymorphism among 28 tomato genotypes. Details of SSR markers are given in Table 2. PCR amplification was carried out in 96 well Universal Gradient Thermal Cycler (Eppendorf, Germany) in a $25 \mu \mathrm{l}$ reaction mixture. The reaction mixture contained $2.5 \mu \mathrm{l}$ of each forward and reverse primers, $1 \mathrm{U}$ of Taq polymerase (D1806- Sigma Aldrich, USA), $5 \mu$ l of 10X PCR buffer with $\mathrm{MgCl}_{2}, 2.5$ $\mathrm{mM}$ of each dNTP (dTTPs, dGTPs, dCTPs, dATPs). Amplifications were performed as follows: Initial denaturation of $4 \mathrm{~min}$ at $94{ }^{0} \mathrm{C}$, followed by 35 cycles of $94{ }^{0} \mathrm{C} 1 \mathrm{~min}, 50-55$ ${ }^{0} \mathrm{C} 1 \mathrm{~min}, 72{ }^{0} \mathrm{C} 2 \mathrm{~min}$ and a final extension of $7 \mathrm{~min}$ at $72{ }^{0} \mathrm{C}$. PCR products were mixed with loading dye $(3-4 \mu \mathrm{l})$. PCR products resolved on $3 \%$ agarose gel were visually examined under UV and documented using gel documentation system (MiniLumi, SigmaSvi Bio Solutions Pvt. Ltd. New Delhi, India). Gels were visually scored and scanned for records. The clear and reproducible alleles amplified by each SSR among 28 genotypes were scored according to their fragment size (bp) corresponding to the $100 \mathrm{bp}$ molecular weight marker (Sigma Aldrich, USA). Amplified fragments were scored as present (1) and absent (0) generating the 0 and 1 
matrix and Polymorphism Information Content (PIC value) was calculated by using the following formula.

$\mathrm{PIC}=2 \mathrm{fi}(1-\mathrm{fi})$

Where,

$\mathrm{fi}=$ frequency of bands present

$1-\mathrm{fi}=$ frequency of bands absent

Pair- wise similarity between the genotypes was estimated using Jaccard's similarity coefficient (Jaccard, 1908). Cluster analysis based on unweighted pair-group method with arithmetic averages (UPGMA) clustering algorithm was performed using NTSYS-pc version 2.02e (Rohlf, 1998) to obtain a dendrogram. The major allele frequency, numbers of alleles, gene diversity, and Polymorphism Information Content (PIC) was analyzed using the Power Marker software ver. 3.23 (Liu and Muse 2005).

\section{Results and Discussion}

\section{Allelic variation based on microsatellite markers}

SSR polymorphisms in these 24 tomato genotypes were measured in terms of major allele frequency, numbers of alleles, gene diversity, and PIC (Table 3) using the Power Marker software ver. 3.23 (Liu and Muse 2005). The 25SSR markers revealed the major allele frequency per locus varied from 0.4091 (SSR66) to 0.9091(SSR96) with an average value of 0.6622 per marker. Above SSR markers revealed 64 alleles among these tomato genotypes. Allelic richness per locus varied widely among the markers, ranging from 2 to 5(SSR139, SSR66 and SSR 47), with an average of 2.720 alleles per locus. The SSR loci (gene) diversity and heterozygosity per locus generated from amplification data and summarized in Table 2. The gene diversity per locus ranged from 0.1694 (SSR96) to 0.7025 (SSR66), with an average value i.e. 0.4548 per marker. The polymorphic information content revealed by each primer are given in same table. The polymorphic Information content (PIC) ranged from 0.160.65 with an average value of 0.38 .

The highest Polymorphic Information content (PIC-0.65) was estimated for primer SSR 139 and SSR66, followed by SSR 47 which had a PIC value of 0.62, whereas primer SSR 96 showed least PIC value i.e. 0.16.

\section{Cluster analysis}

The dendrogram generated from SSR data, the tomato genotypes grouped in three main clusters as represented in Figure 1, in which CO-3 was totally distinguished from other genotypes that had grouped together. Cluster I and II were further divided into two sub clusters and comprised of 15 and 8 genotypes, respectively whereas, Cluster III comprised of single genotype i.e. CO-3. Principal component analysis (PCA) of 24 tomato genotypes using 25 SSR markers revealed similar results as observed by UPGMA based clustering (Figure 2).

Molecular markers have great potential to characterization of crop genotypes (Rai et al., 2016). Molecular characterization is a convenient tool for assessing genetic diversity and characterization of various plant genetic resources with molecular markers offers a unique opportunity to define significant marker-trait associations of biological and agronomic interest (Park et al., 2004; Semagn et al., 2006; Mondini et al., 2009; Parmar 2010). In this study, 25 SSR markers produced 64 alleles and the number of detected alleles over all loci across the genotypes ranged from 2 to 5(SSR139, SSR66 and SSR 47), with an average of 2.720 alleles per locus (Table 3). Similar findings were also reported earlier. 
Table.1 List of Tomato genotypes

\begin{tabular}{|c|l|l|c|l|l|}
\hline S. No. & \multicolumn{1}{|c|}{ Genotypes } & \multicolumn{1}{|c|}{ Source } & S. No. & \multicolumn{1}{|c|}{ Genotypes } & \multicolumn{1}{c|}{ Source } \\
\hline 1. & C0-3 & IIVR, Varanasi & 13. & HisarArun & IIVR, Varanasi \\
\hline 2. & KashiSharad & IIVR, Varanasi & 14. & Azad T-5 & IIVR, Varanasi \\
\hline 3. & WIR-13706 & IIVR, Varanasi & 15. & Pusa Ruby & IIVR, Varanasi \\
\hline 4. & KashiVishesh & IIVR, Varanasi & 16. & Pant-T-3 & IIVR, Varanasi \\
\hline 5. & F-7028 & IIVR, Varanasi & 17. & EC-529083 & IIVR, Varanasi \\
\hline 6. & Roma & IIVR, Varanasi & 18. & S. Vaibhav & IIVR, Varanasi \\
\hline 7. & VRT-32 & IIVR, Varanasi & 19. & EC-501574 & IIVR, Varanasi \\
\hline 8. & Money maker & IIVR, Varanasi & 20. & EC-501575 & IIVR, Varanasi \\
\hline 9. & Flora Dade & IIVR, Varanasi & 21. & Pant- T-7 & IIVR, Varanasi \\
\hline 10. & EC-520071 & IIVR, Varanasi & 22. & VRT-32-792 & IIVR, Varanasi \\
\hline 11. & EC-317-6-1 & IIVR, Varanasi & 23. & F-7012 & IIVR, Varanasi \\
\hline 12. & C-26-1 & IIVR, Varanasi & 24. & ArkaVikash & IIVR, Varanasi \\
\hline
\end{tabular}

Table.2 List of primers used in the study

\begin{tabular}{|c|c|c|c|}
\hline S. No & Primer & Forward Sequence & Reverse Sequence \\
\hline 1 & A1773078 & 5'GATGGACACCCTTCAATTTATGGT3' & 3'TCCAAGTATCAGGCACACCAGC5' \\
\hline 2 & A1778183 & 5'GCGAAGAAGATGAGTCTAGAGCATAG3' & 3'СТСТСТСССАTGAGTTCTCСТCTTC5' \\
\hline 3 & A1895126 & 5'GCTCTGTCCTTACAAAGTATACCTCC3' & 3'CAATGCTGGGACAGAAGATTTAATG5' \\
\hline 4 & A1486387 & 5'ACGCTTGGCTGCCTCGGA3' & 3'AACTTTATTATTGCCACGTAGTCATGA5' \\
\hline 5 & Y09371 & 5'TGAGAACAACGTTTAGAGGAGCTG3' & 3'CGGGCAGAATCTCGAACTC5' \\
\hline 6 & Y08306 & 5'AACGGTGGAAACTATTGAAAGG3' & 3'CACCACCAAACCCCATCGTC5' \\
\hline 7 & X90937 & 5'TGCCCATGACGTTCCATC3' & 3'GACAGACAGAGAGACAGACTTAGAG5' \\
\hline 8 & X90770 & 5'TGTAGATAACTTCCTAGCGACAATC3' & 3'ACGGACGGATGGACAAATG5' \\
\hline 9 & LEttc002 & 5'TTCTCACACCTGCACACACC3' & 3'AGCGGGATGATTACAGAAATG5' \\
\hline 10 & TMS 37 & 5'CCTTGCAGTTGAGGTGAATT3' & 3'TCAAGCACCTACAATCAATCA5' \\
\hline 11 & TMS 48 & 5'ATTGCTCATACATAACCCCC3' & 3'GGGACAAAATGGTAATCCAT5' \\
\hline 12 & SSR 601 & 5'TCTGCATCTGGTGAAGCAAG3' & 3'CTGGATTGCCTGGTTGATTT5' \\
\hline 13 & SSR 139 & 5'TGGGTATGGGATTTACACCAA3' & 3'AAACGAAGGCAACAACGAAG5' \\
\hline 14 & SSR 9 & 5'CCСТTTGCAAGTTCTTCTTCA3' & 3'TTCATGAGCCAACATAGGAGG5' \\
\hline 15 & SSR 50 & 5'CCGTGACCCTCTTTACAAGC3' & 3'TTGCTTTCTTCTTCGCCATT5' \\
\hline 16 & SSR 75 & 5'CCATCTATТАТСТТСТСТССААСАC3' & 3'GGTCCCAACTCGGTACACAC5' \\
\hline 17 & SSR 146 & 5'TATGGCCATGGCTGAACC3' & 3'CGAACGCCACCACTATACCT5' \\
\hline 18 & SSR 66 & 5'TGCAACAACTGGATAGGTCG3' & 3'TGGATGAAACGGATGTTGAA5' \\
\hline 19 & SSR 96 & 5'GGGTTATCAATGATGCAATGG3' & 3'CCTTTATGTCAGCCGGTGTT5' \\
\hline 20 & SSR 111 & 5'TTCTTCССТTCCATCAGTTCT3' & 3'TTTGCTGCTATACTGCTGACA5' \\
\hline 21 & SSR 241 & 5'TCAACAGCATAGTGGAGGAGG3' & 3' TCCTCGGTAATTGATCCACC 5' \\
\hline 22 & SSR 43 & 5'CTCCAAATTGGGCAATAACA3' & 3' TTAGGAAGTTGCATTAGGCCA 5' \\
\hline 23 & SSR 110 & 5'TGTAACGTCAAACTTCAGGTG3' & 3' CTCCGCAATGTGTTGTATGG 5' \\
\hline 24 & SSR 80 & 5'GGCAAATGTCAAAGGATTGG3' & 3’AGGG TGTTCTTGATTGTCA 5' \\
\hline 25 & SSR 47 & 5' TCCTCAAGAAATGAAGCTCTGA3' & 3' CCTTGGAGATAACAACCACAA 5' \\
\hline
\end{tabular}


Table.3 Major allele frequency, number of alleles, gene diversity, heterozygosity and PIC values of primers

\begin{tabular}{|c|c|c|c|c|c|c|}
\hline S. No. & Marker & $\begin{array}{c}\text { Major Allele } \\
\text { Frequency }\end{array}$ & $\begin{array}{c}\text { Allele } \\
\text { No }\end{array}$ & $\begin{array}{c}\text { Gene } \\
\text { Diversity }\end{array}$ & Heterozygosity & PIC \\
\hline $\mathbf{1}$ & $\mathbf{A 1 7 7 3 0 7 8}$ & 0.8250 & 2.0000 & 0.2888 & 0.2500 & 0.2471 \\
\hline $\mathbf{2}$ & $\mathbf{A 1 7 7 8 1 8 3}$ & 0.8478 & 2.0000 & 0.2580 & 0.3043 & 0.2247 \\
\hline $\mathbf{3}$ & $\mathbf{A 1 8 9 5 1 2 6}$ & 0.7308 & 2.0000 & 0.3935 & 0.5385 & 0.3161 \\
\hline $\mathbf{4}$ & A1486387 & 0.7353 & 3.0000 & 0.4135 & 0.4118 & 0.3636 \\
\hline $\mathbf{5}$ & Y09371 & 0.7273 & 2.0000 & 0.3967 & 0.5455 & 0.3180 \\
\hline $\mathbf{6}$ & Y08306 & 0.5750 & 2.0000 & 0.4888 & 0.8500 & 0.3693 \\
\hline $\mathbf{7}$ & X90937 & 0.6071 & 2.0000 & 0.4770 & 0.7857 & 0.3633 \\
\hline $\mathbf{8}$ & X90770 & 0.8636 & 2.0000 & 0.2355 & 0.2727 & 0.2078 \\
\hline $\mathbf{9}$ & LEttc002 & 0.7750 & 2.0000 & 0.3488 & 0.1500 & 0.2879 \\
\hline $\mathbf{1 0}$ & TMS 37 & 0.5952 & 2.0000 & 0.4819 & 0.8095 & 0.3658 \\
\hline $\mathbf{1 1}$ & TMS 48 & 0.7368 & 2.0000 & 0.3878 & 0.0000 & 0.3126 \\
\hline $\mathbf{1 2}$ & SSR601 & 0.5357 & 2.0000 & 0.4974 & 0.9286 & 0.3737 \\
\hline $\mathbf{1 3}$ & SSR 139 & 0.4706 & 5.0000 & 0.6990 & 0.0000 & 0.6595 \\
\hline $\mathbf{1 4}$ & SSR 9 & 0.6190 & 2.0000 & 0.4717 & 0.0000 & 0.3604 \\
\hline $\mathbf{1 5}$ & SSR 50 & 0.7500 & 3.0000 & 0.4063 & 0.0000 & 0.3706 \\
\hline $\mathbf{1 6}$ & SSR 75 & 0.5714 & 3.0000 & 0.5533 & 0.0000 & 0.4728 \\
\hline $\mathbf{1 7}$ & SSR 146 & 0.6000 & 3.0000 & 0.5588 & 0.1500 & 0.4971 \\
\hline $\mathbf{1 8}$ & SSR 66 & 0.4091 & 5.0000 & 0.7025 & 0.0000 & 0.6526 \\
\hline $\mathbf{1 9}$ & SSR 96 & 0.9091 & 3.0000 & 0.1694 & 0.0909 & 0.1626 \\
\hline $\mathbf{2 0}$ & SSR 111 & 0.8182 & 2.0000 & 0.2975 & 0.3636 & 0.2533 \\
\hline $\mathbf{2 1}$ & SSR 241 & 0.5833 & 3.0000 & 0.5590 & 0.2500 & 0.4878 \\
\hline $\mathbf{2 2}$ & SSR 43 & 0.6957 & 2.0000 & 0.4234 & 0.4348 & 0.3338 \\
\hline $\mathbf{2 3}$ & SSR 110 & 0.5714 & 4.0000 & 0.5975 & 0.1429 & 0.5456 \\
\hline $\mathbf{2 4}$ & SSR 80 & 0.5500 & 3.0000 & 0.5850 & 0.0000 & 0.5129 \\
\hline $\mathbf{2 5}$ & SSR 47 & 0.4524 & 5.0000 & 0.6791 & 0.6190 & 0.6274 \\
\hline & Mean & 0.6622 & 2.7200 & 0.4548 & 0.3159 & 0.3875 \\
\hline & & & & & \\
\hline & & & & & \\
\hline & & & & & & \\
\hline
\end{tabular}

Fig.1 Dendrogram of 24 tomato genotypes produced by UPGMA clustering method based on the genetic similarity

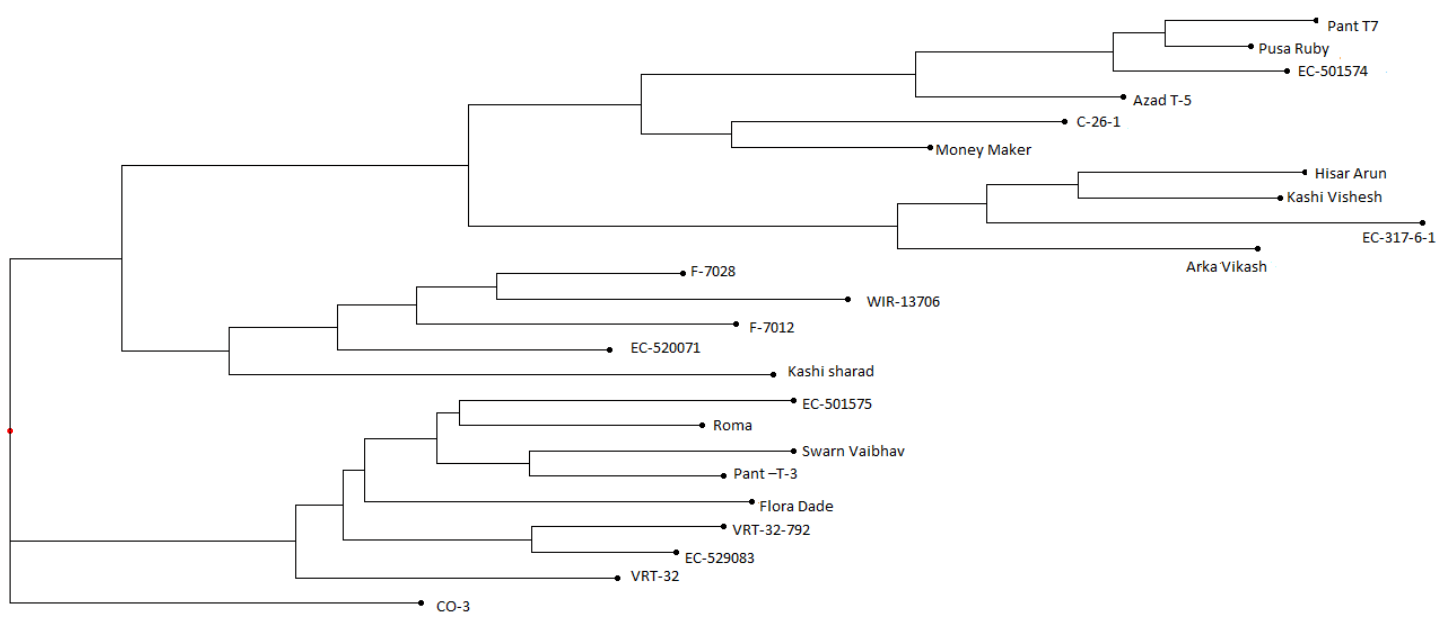


Fig.2 Principal Component Analysis (PCoA) of 24 tomato genotypes

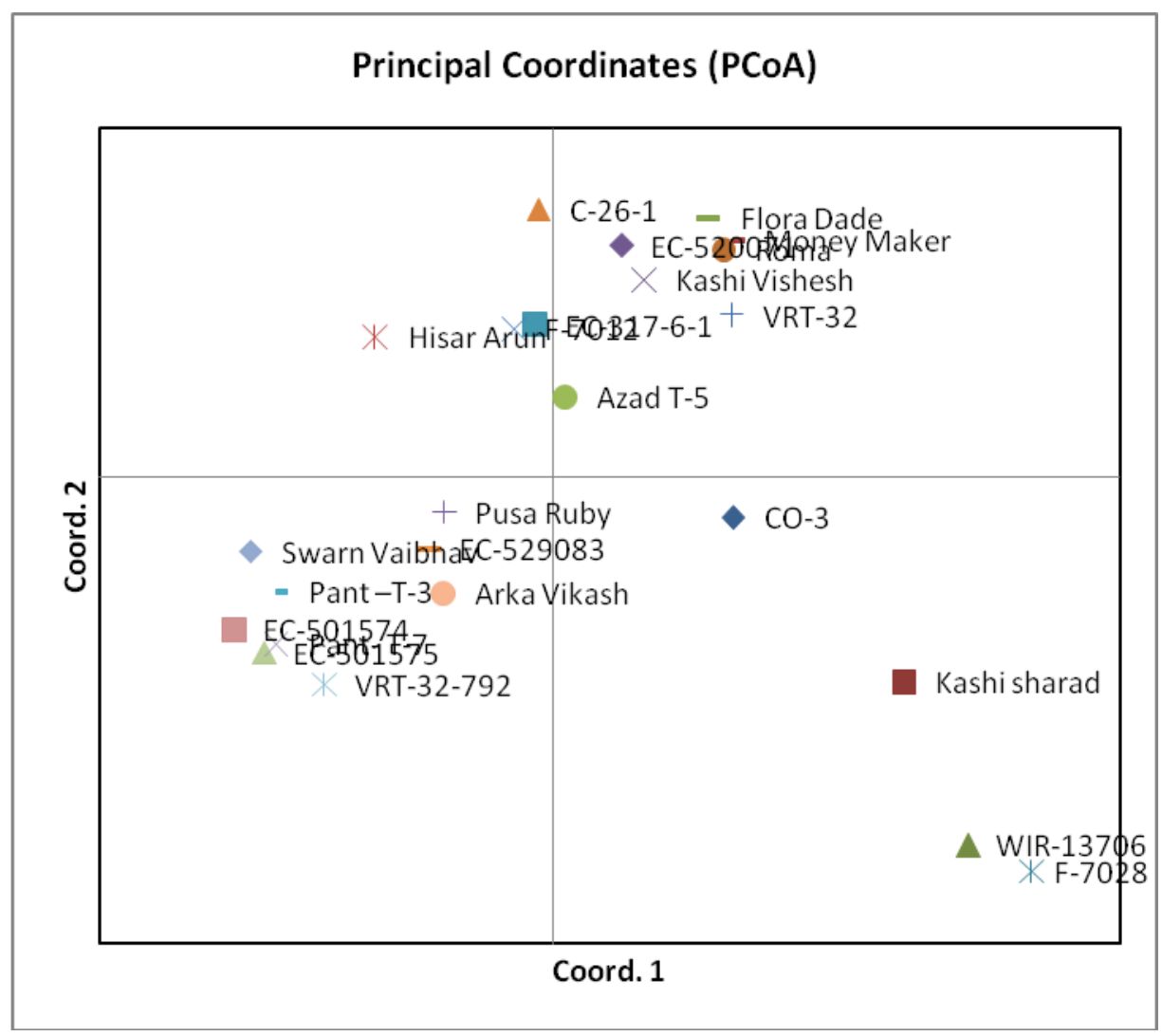

For example, Raveendar et al., (2016) were reported that, total of 176 alleles were detected at an average of ten alleles per SSR locus. Bredemeijer et al., (2002) have reported a mean number of 4.7 (range, 2-8) alleles per locus in 521 tomato accessions. Todorovska et al., (2014) have reported a mean number of 1.8 (range, 1-6) alleles per locus in eight Bulgarian tomato accessions. Benor et al., (2008) have reported an average of 4.3 alleles per locus in 39 determinant and in determinant tomato inbred lines. Smulders et al., (1997) have detected 3 alleles per locus on average for 7 inbred lines of tomato. He et al., (2003) have identified 2.7 alleles per locus on average among 17 varieties and 2 parental lines of tomatoes. Major allele frequency per locus varied from 0.4091 to 0.9091 (SSR96) with an average value of 0.6622 per marker. Gene diversity and heterozygosity per locus generated from amplification data and summarized in Table 3 . The gene diversity per locus ranged from 0.1694 (SSR96) to 0.7025 (SSR66), with an average value i.e. 0.4548 per marker. Raveendar et al., (2016) were reported that the average major allele frequency i.e. 0.69 in 355 accession of tomato. The PIC value of each SSR locus was used to assess their level of in-formativeness (high, PIC greater than0.5; moderate, 0.5 greater than PIC greater than 0.25; low, PIC less than 0.25) (Botstein et al., 1980). To compare the genetic variabilities among the genotypes, we calculated PIC and heterozygosity of SSR primers used. The average PIC and heterozygosity were 0.3875 and 0.3159 , respectively. Raveendar et al., (2016) was reported that polymorphic information content were 0.39 for 355 Asian tomato accessions. Todorovska et al., (2014) have reported an average PIC and GD value of 
0.196 and 0.22, respectively, for Bulgarian tomato accessions. Compared to these reports, our result revealed higher level of mean PIC $(0.0 .3875)$ and heterozygosity value (0.0.3159). Therefore, our results will be useful for further genetic studies on tomato species. The genetic distance-based results observed in the dendrogram revealed a similar trend to the genetic similarity analysis, revealing genotypes were grouped into three clusters i.e., I, II and III, but it was not possible to distinguish among genotypes with different species (Figure 1).

Cluster I and II were further divided into two sub clusters and comprised of 15 and 8 genotypes, respectively. Whereas, Cluster III comprised of single genotype i.e. CO-3.PCoA analysis was also consistent with the clustering results (Figure 2).

It is concluded that SSR markers are effective in unravelling the genetic diversity within the tomato lines. The genetic diversity observed within the tomato genotypes will prove to be of utmost importance for germplasm classification, management, and further utilization in tomato breeding programmes.

\section{Acknowledgements}

The Authorsare sincerely thankful to School of Biotechnology, Sher-e-Kashmir University of Agricultural Sciences and Technology of Jammu, Chatha, Jammu (J\&K), India and Indian Institute of Vegetable Research (IIVR), Varanasi, UP, India for providing the genotypes and support.

\section{References}

Agong S. G., Schittenhelm S. and Friedt W. 2001. Genotypic variation of Kenyan tomato (Lycopersicon esculentum L.) germplasm. Journal of Food Technol. Africa. 6:13-17.

Al-Aysh F., Kutma H. and Al- Zouabi A. 2012. Genetic variation, heritability and interrelationships of some important characteristics in Syrian tomato landraces (Solanum lycopersicum L.). Acad. Arena. 4:1-5.

Benor S., Zhang M., Wang Z. and Zhang H. 2008. Assessment of genetic variation in tomato (Solanum lycopersicum L.) inbred lines using SSR molecular markers. J. Genet. Genomics. 35: 373-379.

Botstein, D., White R.L., Skolnick M., and Davis R.W. 1980. Construction of a genetic linkage map in man using restriction fragment length polymorphisms. Am. $J$. Hum. Genet. 32:314-331.

Bredemeijer M., Cooke J., Ganal W., Peeters R., Isaac P., Noordijk Y., et al., 2002. Construction and testing of a microsatellite database containing more than 500 tomato varieties. Theor. Appl. Genet. 105: 10191026.

Foolad M. 2007. Genome mapping and molecular breeding of tomato. International Journal of Plant Genomics. 52: 643- 658.

Frary A., Xu Y., Liu J., Mitchell S., Tedeschi E. and Tanksley S 2005. Development of a set of PCR-based anchor markers encompassing the tomato genome and evaluation of their usefulness for genetics and breeding experiments. Theoretical and Applied Genetics 111:291-312.

He C., Poysa V. and Yu K. 2003. Development and characterization of simple sequence repeat (SSR) markers and their use in determining relationships among Lycopersicon esculentum cultivars. Theoretical and Applied Genetics. 106:363373.

Liu K. and Muse S. V. 2005. Power Marker: an integrated analysis environment for genetic marker analysis. Bioinformatics. 21: 21282129.

Mazzucato A., Papa R., Bitocchi E., Mosconi P., Nanni L., Negri V., Picarella M.E., Siligato F., Soressi G.P., Tiranti B. and Veronesi F 2008. Genetic diversity, structure and marker-trait associations in a collection of Italian tomato (Solanum lycopersicum L.) landraces. Theoretical and Applied Genetics.116:657-669.

Mondini L., Noorani A. and Pagnotta A. Mario. 2009. Assessing plant genetic diversity by 
molecular tools. Diversity. 1: 19-35.

Naz S., Zafrullah A., Shahzadhi K. and Munir N. 2013. Assessment of genetic diversity within germplasm accessions in tomato using morphological and molecular markers. The Journal of Animal \& Plant Sciences. 23:1099-1106.

Osei M. K., Bonsu K. O., Agyeman A. and Choi H. S. 2014. Genetic diversity of tomato germplasm in Ghana using morphological characters. International Journal of Plant Soil Science. 3: 220-231.

Park Y.H., West M.A.L. and St. Clair D.A. 2004. Evaluation of AFLPs for germplasm fingerprinting and assessment of genetic diversity in cultivars of tomato (Lycopersicon esculentum L.). Genome 47:510-518.

Parmar P., Oza P. Vishal., Chauhan V. and Patel A.D., Kathiria K.B., Subramanian R.B. 2010. Genetic diversity and DNA fingerprint study of tomato discerned by SSR markers. Int. J. Biotechnol. Biochem. 6: 657-666.

Rai G. K., Kumar R., Singh A. K., Rai P. K., Rai M., Chaturvedi A. K. and Rai A. B. 2012. Changes in antioxidant and phytochemical properties of tomato (Lycopersicon esculentum Mill.) under ambient condition. Pakistan Journal of Botany. 44: 667-670.

Rai G.K., Jamwal D., Singh S., Parveen A., Kumar R.R., Singh M., Rai P.K. and Salgotra R.K. 2016. Assessment of genetic variation in tomato (Solanum lycopersicum L.) based on quality traits and molecular markers. SABRAO Journal of Breeding and Genetics.48: 80- 89.

Raveendar S., Jong-Wook Chung, Gi-An Lee1,
Jung-Ro Lee1, Kyung-Jun Lee1, MyoungJae Shin, Yang-Hee Cho and Kyung-Ho M. 2016. Genetic Diversity and Population Structure of Asian Tomato. Accessions Based on Simple-Sequence Repeats. Plant Breed. Biotech. 4(3):306-314.

Reddy B. R., Reddy M. P., Begum, H. and Sunil N. 2013. Genetic diversity studies in tomato (Solanum lycopersicum L.). Journal of Agriculture and Veterinary Science. 4:5355.

Rohlf F. J., NTSYS-pc 1998. Numerical taxonomy and multivariate analysis system. Applied Biostatistics (New York).

Semagn K., Bjornstad A. and Ndjiondjop Mn. 2006. An overview of molecular marker methods for plants. Afr. J. Biotechnol. 5(25): 2540-2568.

Smulders M.J.M., Bredemeijer G., Rus-Kortekaas W., Arens P. and Vosman B. 1997. Use of short microsatellites from database sequences to generate polymorphisms among Lycopersicon esculentum cultivars and accessions of other Lycopersicon species. Theor. Appl. Genet. 94: 264-272.

Song J., Chen J., Chen H. Y., Liu Y. and Zhuang T. M. 2006. Research of genetic diversity of tomato using SSR markers. Journal of Shanghai Jiao tong University. 24:524-528.

Todorovska E., Ivanova A., Ganeva D., Pevicharova G., Molle E., Bojinov B., et al., 2014. Assessment of genetic variation in Bulgarian tomato (Solanum lycopersicum L.) genotypes, using fluorescent SSR genotyping platform. Biotechnol. Biotechnol. Equip. 28: 68-76.

\section{How to cite this article:}

Pooja Choudhary, Gyanendra Kumar Rai, Sreshti Bagati, Deeksha Jamwal, Diksha Bhadwal, Vibha Raj Shanti and Pradeep Kumar Rai. 2018. Evaluation of Genetic Variability in Tomato (Solanum lycopersicum L. Mill) Genotypes using Microsatellite Markers. Int.J.Curr.Microbiol.App.Sci. 7(01): 2117-2124. doi: https://doi.org/10.20546/ijcmas.2018.701.255 